\title{
Effectiveness and controversy of convalescent plasma therapy for COVID-19 patients
}

\author{
zhanjun $\mathrm{Shu}^{1}$, xin $\mathrm{Da}^{2}$, qianqian $\mathrm{Qian}^{3}$, dandan $\mathrm{Du}^{4}$, and ke Wang ${ }^{5}$ \\ ${ }^{1}$ the fourth affiliated hospital of xinjiang medical university \\ ${ }^{2}$ Central Hospital of Karamay \\ ${ }^{3}$ the eighth affiliated hospital of xinjiang medical university \\ ${ }^{4}$ xinjiang medical university \\ ${ }^{5}$ Guangdong Tuberculosis Control Center, Shipai Village, Huangpu Dadao, Tianhe District, \\ Guangzhou City, Guangdong Province
}

November 19, 2020

\begin{abstract}
Coronavirus disease2019(COVID-19) is a pandemic with no specific therapeutic agents and substantial mortality. It is critical to find new treatments. Convalescent plasma, donated by persons who have recovered from COVID-19, is the acellular component of blood that contains antibodies, including those that specifically recognize SARS-CoV-2. Therefore, for COVID-19 patients, Convalescent plasma, could prove lifesaving, such as improving the clinical symptoms, increasing the neutralizing antibody, decreasing the viral load, reducing the death rate, with safety and without seriously ADE. Meanwhile, it is urgent to perform large sample randomized controlled trials to confirm the transfusion timing, dosage, frequency and actively prevent adverse outcomes that may occur, establishing a standard procedure for treatment from convalescent plasma collection, preservation, transport, to transfusion.
\end{abstract}

\section{Hosted file}

Effectiveness and controversy of convalescent plasma therapy for COVID-19 patients1.pdf available at https://authorea.com/users/377282/articles/494004-effectiveness-andcontroversy-of-convalescent-plasma-therapy-for-covid-19-patients

\section{Hosted file}

figure1.pdf available at https://authorea.com/users/377282/articles/494004-effectiveness-andcontroversy-of-convalescent-plasma-therapy-for-covid-19-patients

\section{Hosted file}

feigure 2.pdf available at https://authorea.com/users/377282/articles/494004-effectivenessand-controversy-of-convalescent-plasma-therapy-for-covid-19-patients 